\title{
PENGOLAHAN RUMPUT LAUT (Eucheuma cottoni) MENJADI DAWET RUMPUT LAUT
}

\author{
Illiyatus Sholiha \\ Program Studi Teknologi Hasil Perikanan \\ Fakultas Pertanian Universitas Yudharta Pasuruan \\ email: illiyatus.sholiha@gmail.com
}

\begin{abstract}
ABSTRAK
Diversifikasi produk rumput laut jenis Eucheuma cottoni menjadi minuman khas daerah berupa dawet. Penelitian bertujuan untuk menghasilkan dawet rumput laut Eucheuma cottoni serta mengetahui perbandingan jumlah rumput laut dalam adonan dawet yang menghasilkan tekstur, aroma, dan rasa dawet yang disukai. Penelitian dilakukan dengan cara pembuatan bubur rumput laut dan adonan dawet. Perlakuan digunakan dalam penelitian ini untuk mengetahui perbandingan rumput laut dan adonan agar mendapatkan dawet rumput laut yang paling disukai oleh panelis. Perlakuan yang digunakan dalam penelitian ini adalah menggunakan perbandingan antara bubur rumput laut dan adonan dawet antara lain, P1 (0\%): adonan dawet 500 gram, P2 (50\%): adonan dawet 500 gram dan bubur rumput laut 250 gram, P3 (70\%): adonan dawet 500 gram dan bubur rumput laut 350 gram, dan P4 (90\%):adonan dawet 500 gram dan bubur rumput laut 450 gram. Selanjutnya masing-masing perlakuan dimasak hingga matang dan menjadi adonan dawet rumput laut yang siap untuk dicetak. Adonan dicetak dalam keadaan panas menggunakan cetakan dawet diatas air matang yang sudah diberi es.Produk akhir yang dihasilkan selanjutnya diuji organoleptik untuk mengetahui kesukaan panelis terhadap tekstur, aroma, dan rasa dawet yang dihasilkan. Hasil uji organoleptik selanjutnya dianalisis secara deskriptif dan analisis sidik ragam (Anova). Hasil analisis kesukaan panelis terhadap tekstur, aroma, dan rasa serta dawet rumput rumput laut secara keseluruhan menunjukkan dawet rumput laut terbaik adalah P3 (70\%). Hasil analisis sidik ragam (Anova) menunjukkan tidak ada beda yang nyata penambahan rumput laut terhadap tekstur, aroma, dan rasa dawet yang dihasilkan antara masing-masing perlakuan P1, P2, P3, dan P4.
\end{abstract}

Kata kunci: dawet, Eucheuma cottoni, organoleptik, rumput laut

\section{PENDAHULUAN}

Indonesia sebagai negara maritim yang beriklim tropis memberikan keuntungan yaitu memiliki berbagai jenis biota laut yang melimpah termasuk rumput laut. Rumput laut disebut juga alga laut, dalam sistem taksonomi merupakan anggota dari kingdom Protista dari kelompok fitoplankton. Fitoplankton menduduki peranan penting di perairan karena merupakan sumber oksigen bagi biota air lainnya. Keunikan yang dimiliki oleh rumput laut adalah kekhasan pigmen yang dimiliki sehingga menjadi dasar klasifikasinya yaitu Divisi Rhodophyta (alga merah), Chlorophyta (alga hijau), Phaeophyta (alga coklat), dan Chrysophyta (alga pirang/keemasan). Kebutuhan terhadap pangan fungsional saat ini semakin meningkat seiring dengan meningkatnya kesadaran masyarakat terhadap kesehatan. Salah satu ciri bahan pangan yang dapat dikembangkan menjadi pangan fungsional adalah mengandung PUFA, serat, dan antioksidan [1]. Green food atau produk makanan berpigmen juga berfungsi sebagai pangan fungsional karena banyak mengandung serat, nutrisi, dan antioksidan untuk detoksifikasi bahkan anti kanker [2]. Penelitian mengenai kandungan rumput laut sebagai salah satu bahan pangan fungsional sudah banyak dilakukan. Rumput laut memiliki kandungan serat dan nutrisi yang bermanfaat sebagai antioksidan, antimutagenik, antikoagulan, anti tumor, dan metabolisme lipid serta sebagai sumber iodium alami yang terbaik [3]. Rumput laut juga dapat menjadi produk makanan sebagai sumber pigmen dan antioksidan alami bagi tubuh. Alga merah memiliki warna talus yang bervariasi disebabkan komposisi pigmen yang dimiliki yaitu klorofil a, klorofil b, dan fikobiliprotein (R-fikosianin, allofikosianin, dan fikoeritrin) [1]. 
Salah satu jenis rumput laut yang banyak dijual di pasar adalah Eucheuma cottoni. Rumput laut Eucheuma cottoni merupakan anggota Rhodophyta yang memiliki bentuk talus bulat silindris atau gepeng dan bercabang-cabang. Percabangan talus sederhana sampai kompleks dengan ujung percabangannya ada yang tumpul dan ada yang runcing. Permukaan talus agak kasar karena mempunyai gerigi dan berbintil-bintil. Warna talus kuning kecoklatan sampai merah ungu. Eucheuma cottoni banyak ditanam di Indonesia. Eucheuma hidup di laut dangkal, berpasir, berlumpur, atau pasir berlumpur. Alga ini menempel batu karang yang sudah mati, kerang, maupun benda-benda yang mengandung kapur dan banyak tersebar di perairan laut Maluku, Serang, Jawa dan Bali [4].

Mengingat pentingnya rumput laut sebagai bahan pangan fungsional untuk kesehatan maka berbagai olahan rumput laut perlu lebih didekatkan pada masyarakat. Rumput laut Eucheuma cottonibiasanya masih dikonsumsi secara langsung sebagai bahan isian tambahan dalam minuman es rumput laut. Rumput laut dalam minuman es rumput laut ditambahkan setelah melewati perlakuan dicuci, direndam, dan diberi pewarna. Rumput laut tersebut dikonsumsi bersama dengan beberapa irasan buah seperti nanas, pepaya, dan alpukat serta isian lain yaitu kolang-kaling dan agar-agar. Dawet merupakan salah satu contoh minuman yang banyak digemari karena rasanya yang khas dan nikmat. Dawet merupakan salah satu minuman khas asli Indonesia. Dawet pada umumnya dibuat dari tepung beras yang disajikan dengan larutan gula merah dan santan. Setiap daerah memiliki ciri khas tersendiri untuk minuman dawet contohnya Dawet Ayu dari Banjarnegara dan Dawet Jabung dari Ponorogo.

Pengolahan rumput laut Eucheuma cottoni juga dapat diolah menjadi dawet yang yang sudah banyak digemari serta mudah dibuat oleh masyarakat. Dengan demikian, diharapkan masyarakat mendapatkan kandungan manfaat yang terdapat di dalam rumput laut melalui jajanan minuman yang sudah digemari dalam keseharian berupa dawet. Penelitian bertujuan untuk membuat dawet rumput laut Eucheuma cottoni serta mengetahui perbandingan jumlah rumput laut dalam adonan dawet yang menghasilkan tekstur, aroma, dan rasa dawet yang disukai.

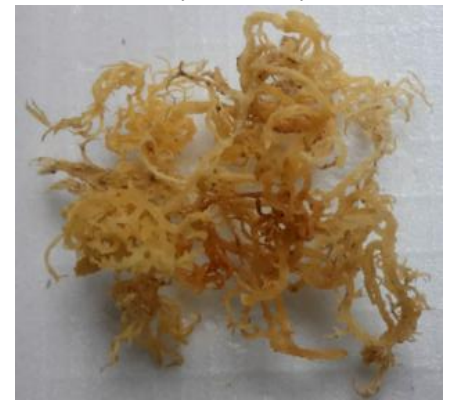

Gambar 1. Rumput Laut (Eucheuma cottoni) sebagai Sampel Penelitian

\section{METODE PENELITIAN}

Bahan dalam pembuatan dawet rumput laut adalah rumput laut Eucheuma cottoni keringyang dibeli dari toko bahan pangan setempat, tepung beras, Nutrijell, tepung HunKwe, air, kelapa, gula merah, gula pasir, garam, daun pandan. Alat yang dibutuhkan antara lain panci, spatula, kompor, timbangan, gelas ukur, cetakan dawet, baskom, pisau, telenan, mangkok, dan pengaduk kayu. Penelitian dilakukan dengan cara pembuatan bubur rumput laut dan adonan dawet telebih dahulu. Bubur rumput laut dibuat dengan cara rumput laut kering dicuci dibawah air mengalir sampai bersih lalu dipotong dengan ukuran panjang $0,5 \mathrm{~cm}$ sampai $1 \mathrm{~cm}$. Rumput laut yang telah dipotong dimasukkan ke dalam panci, ditambah air sampai terendam, lalu direbus dengan api sedang sambil terus diaduk hingga mendidih. Setelah mendidih, api segera dimatikan dan dibiarkan hingga dingin. Adonan dawet dibuat dengan cara tepung Hun Kwe dicampur dengan tepung beras dan bubuk agar-agar jeli terlebih dahulu di dalam mangkok. Setelah tepung tercampur rata, dilarutkan dengan air sambil diaduk hingga terlarut sempurna. Selanjutnya larutan tepung tersebut 
dimasukkan ke dalam panci dan dimasak dengan api kecil sambil terus diaduk hingga menjadi adonan dawet setengah matang.

Adonan dawet dan bubur rumput laut dibagi menjadi beberapa perlakuan yaitu P1 (0\%): adonan dawet 500 gram, P2 (50\%): adonan dawet 500 gram dan bubur rumput laut 250 gram, P3 (70\%): adonan dawet 500 gram dan bubur rumput laut 350 gram, dan P4 (90\%): adonan dawet 500 gram dan bubur rumput laut 450 gram. Selanjutnya masing-masing perlakuan dimasak hingga matang dan menjadi adonan dawet rumput laut yang siap untuk dicetak. Adonan dicetak dalam keadaan panas menggunakan cetakan dawet di atas air matang yang sudah diberi es. Sebagai minuman, dawet rumput laut disajikan dengan santan dan larutan gula merah. Santan dibuat dengan cara kelapa diparut, ditambahkan air lalu diperas sampai air perasan bening. Santan yang dihasilkan ditambah gula pasir dan direbus dengan api sedang dengan terus diaduk sampai mendidih agar santan tidak pecah. Larutan gula merah dibuat dengan cara gula merah diiris tipis-tipis lalu dilarutkan di dalam air sambil dimasak hingga mendidih.

Produk akhir yang dihasilkan selanjutnya diuji organoleptik untuk mengetahui tingkat kesukaan terhadap tekstur, aroma, dan rasa dawet yang dihasilkan. Panelis yang dilibatkan berjumlah tujuh belas panelis. Hasil uji organoleptik selanjutnya dianalisis secara deskriptif dan analisis sidik ragam (Anova).

\section{HASIL DAN PEMBAHASAN}

Uji organoleptik yang dilakukan ada dua macam yaitu uji kesukaan pada biji dawet rumput laut serta kesukaan pada minuman dawet rumput laut secara keseluruhan setelah disajikan dengan santan dan larutan gula merah. Kesukaan panelis pada tekstur, aroma, dan rasabiji dawet yang dihasilkan disajikan pada Gambar 2. Berdasarkan Gambar 2 diketahui bahwa tekstur rumput laut terbaik adalah P2, aroma dawet rumput laut terbaik adalah P3, dan rasa dawet rumput laut terbaik adalah P2. Sedangkan P1 adalah dawet tanpa penambahan bubur rumput laut (kontrol).

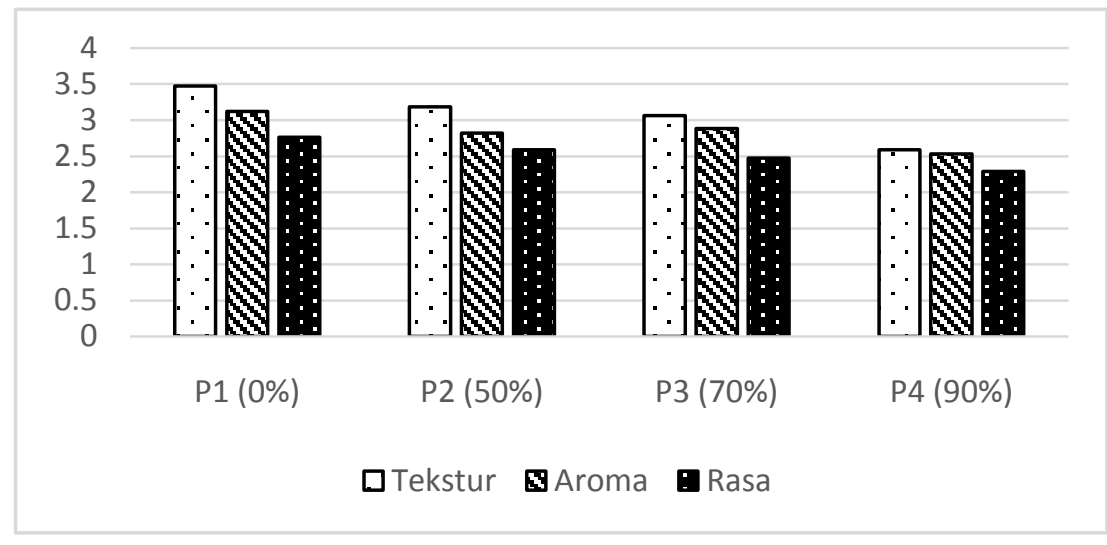

Gambar 2. Hasil Uji Organoleptik Biji Dawet Rumput Laut

Hasil uji kesukaan pada dawet secara keseluruhan setelah disajikan dengan santan dan larutan gula merah ditunjukkan pada Gambar 3. Gambar 3 menunjukkan bahwa dawet rumput laut yang paling disukai oleh panelis adalah P3.

a. Tekstur

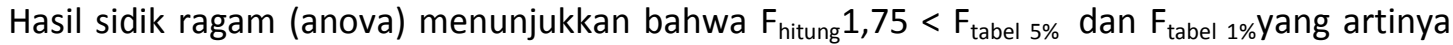
tidak ada beda nyata penambahan rumput laut terhadap teksturbiji dawet yang dihasilkan antara masing-masing perlakuan. Namun hasil analisis deskriptif pada tekstur biji dawet yang ditunjukkan Gambar 1, bahwa tekstur biji dawet rumput laut terbaik adalah P2.Pada perlakuan tersebut dihasilkan tekstur yang lembut, tidak kasar, dan mudah dikunyah. Sedangkan kesukaan terus menurun pada P3 dan P4. Semakin banyak bubur rumput laut yang ditambahkan pada adonan dawet maka tekstur biji dawet yang dihasilkan akan semakin keras dan mudah patahsehingga 
mengurangi kesukaan panelis. Selaras dengan penelitian Hudaya [5], penambahan rumput laut akan menghasilkan tekstur yang tidak kompak sebab tepung rumput laut memiliki partikel yang tidak kompak. Sama halnya dengan pendapat Jaziri [6] bahwa semakin banyak tepung rumput laut yang ditambahkan maka tekstur mie menjadi kurang kenyal dan mudah patah.

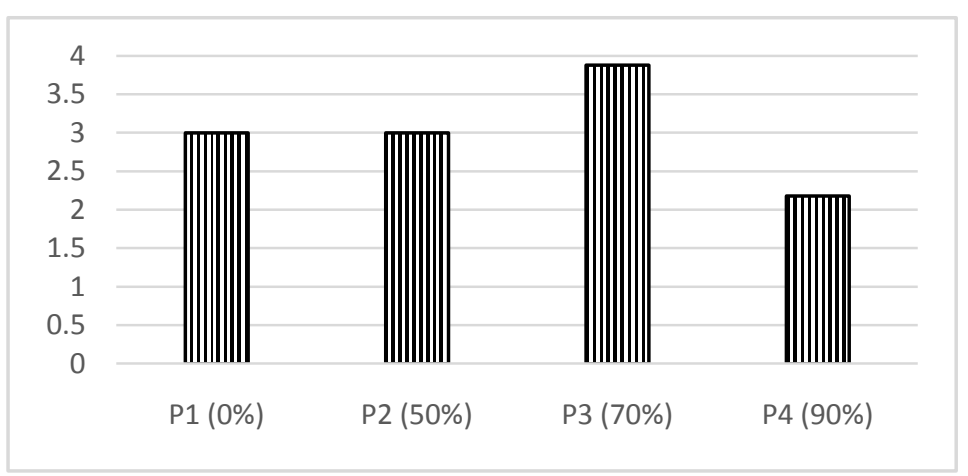

Gambar 3. Hasil Uji Organoleptik MinumanDawet Rumput Laut

\section{b. Aroma}

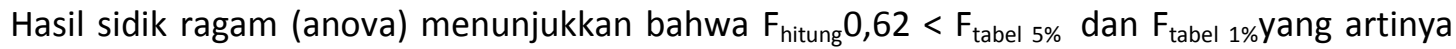
tidak ada beda nyata penambahan rumput laut terhadap aroma biji dawet yang dihasilkan antara masing-masing perlakuan. Namun hasil analisis deskriptif pada aroma biji dawet yang ditunjukkan Gambar 1 bahwa aroma biji dawet rumput laut terbaik adalah P3.Pada perlakuan tersebut dihasilkan perpaduan aroma yang seimbang antara tepung dan rumput laut serta tidak adanya bau khas dari rumput laut (amis). Sedangkan pada P4 kesukaan pada aroma biji dawet menurun karena adanya sedikit aroma khas dari rumput laut. Aroma dari makanan akan mempengaruhi selera. Sesuai dengan penemuan Santoso [7] bahwa nilai aroma akan semakin menurun disebabkan rumput laut memiliki aromayangkhas yaitu bau amis air laut sehingga relatif kurang disukai. Umumnya pati dari tanaman akan membawa bau (off odor) yang berhubungan dengan sumber tanaman [8]. Aroma makanan akan menentukan kelezatan bahan makanan serta dapat memberikan rangsangan terhadap penerimaan konsumen pada suatu produk [9].

c. Rasa

Hasil sidik ragam (anova) menunjukkan bahwa $F_{\text {hitung }} 0,19<\mathrm{F}_{\text {tabel } 5 \%}$ dan $\mathrm{F}_{\text {tabel } 1 \% \text { yang artinya }}$ tidak ada beda nyata penambahan rumput laut terhadap rasa biji dawet yang dihasilkan antara masing-masing perlakuan. Namun hasil analisis deskriptif pada niali organoleptik rasa biji dawet yang ditunjukkan Gambar 1 bahwa rasa biji dawet rumput laut terbaik adalah P2. Rasa yang dihasilkan seimbang antara rasa tepung dan rasa rumput lautnya. Nilai kesukaan terus menurun seiring dengan penambahan jumlah bubur rumput laut pada adonan sehingga P4 menunjukkan nilai kesukaan paling rendah. Hal tersebut dikarenakan seiring dengan penambahan bubur rumput laut maka akan menurunkan dominasi rasa dari tepung. Rasa rumput laut yang terasa lebih dominan yaitu dalam biji dawet P4. Hal tersebut diduga karena perbedaan komposisi zat gizi karbohidrat yang terdapat pada tiga bahan utama dalam pembuatan dawet rumput laut yaitu tepung beras dan tepung Hun Kwe serta rumput laut sehingga mempengaruhi rasa biji dawet yang dihasilkan. Sesuai dengan hasil penelitian Winarno [9], bahwa rasa dari suatu bahan makanan juga dapat dipengaruhi oleh kandungan karbohidrat yang terdapat di dalam bahan makanan.

Mengacu pada hasil uji kesukaan pada Gambar 2, rasa santan yang dipadu dengan rasa manis dari larutan gula merah, ternyata lebih disukai oleh panelis jika dipadukan dengan biji dawet P3. Hal tersebut dikarenakan tekstur dan rasa biji dawet pada P3 setelah dipadu dengan santan menjadi paling dapat diterima panelis. Hal tersebut dikarenakan kandungan lemak di dalam santan menambahkelezatan pada dawet. Santan kelapa juga memiliki aroma yang disukai sehingga dapat meningkatkan selera. Seperti yang dikemukakan oleh Michael [10], lemak membuat makanan lebih lezat. Lemak menyediakan dasar bagi serangkaian luas senyawa larut dalam lemak yang memberi 
rasa karena lemak lebih mudah melintasi membran sel indra pengecap. Sesuai dengan pendapat tersebut, sebagian lipid ada dalam bahan pangan dan sangat mempengaruhi sifat sensoris produk pangan [8]. Larutan gula merah dan gula pasir yang ditambahkan berfungsi sebagai pemanis alami sekaligus untuk meningkatkan kenikmatan dalam mengkonsumsi minuman dawet. Menurut Cahyadi [11], bahan pemanis ditambahkan dengan tujuan untuk memperbaiki rasa dan bau bahan pangan sehingga rasa manis yang timbul dapat meningkatkan kelezatan. Komposisi zat gizi dan karbohidrat rumput laut pada P3 juga berperan dalam membentuk rasa dalam makanan. Hal ini sesuai dengan pendapat Wiranto [9], bahwa rasa dari suatu bahan makanan juga dapat dipengaruhi oleh kandungan karbohidrat yang terdapat di dalam bahan makanan. Hasil penelitian juga membuktikan bahwa penambahan rumput laut yang terlalu banyak akan menurunkan cita rasa minuman dawet meskipun sudah diberi santan dan larutan gula merah seperti yang ditunjukkan dari nilai P4 kurang disukai oleh panelis. Hal tersebut dikarenakan aroma khas rumput laut (amis) yang lebih kuat yang mempengaruhi cita rasa produk dan menurunkan selera.

\section{SIMPULAN}

Tekstur biji dawet terbaik adalah P2, semakin banyak rumput laut yang ditambahkan pada adonan dawet maka tekstur biji dawet yang dihasilkan akan semakin keras sehingga mudah patah. Aroma biji dawet rumput laut terbaik adalah P3, penambahan rumput laut yang semakin banyak (P4) maka menurunkan aroma disebabkan rumput laut memiliki aroma habitatnya yang khas yaitu bau amis air laut sehingga relatif kurang disukai. Rasa biji dawet rumput laut terbaik adalah P2, rasa yang dihasilkan seimbang antara rasa tepung dan rasa rumput lautnya.

Biji dawet yang sudah disajikan dengan santan dan larutan gula merah menujukkan nilai kesukaanterbaikyaitu P3. Hal tersebut dikarenakan kandungan lemak di dalam santan menambah kelezatan pada minuman dawet. Santan kelapa juga memiliki aroma yang disukai sehingga dapat meningkatkan selera.Larutan gula yang ditambahkan sebagai pemanis alami juga meningkatkan kenikmatan dalam mengkonsumsi minuman dawet.P4 kurang disukaidikarenakan aroma khas rumput laut (amis) yang lebih kuat yang mempengaruhi cita rasa produk dawet dan menurunkan selera.

Hasil penelitian ini dapat dikembangkan menjadi bahan ajar Biologi berkaitan dengan pemanfaatan makroalga. Penelitian lanjutan dapat dilakukan analisis kandungan gizi dari produk biji dawet rumput laut dan minuman dawet rumput laut yang dihasilkan.

\section{UCAPAN TERIMA KASIH}

Penulis menyampaikan terima kasih kepada mahasiswa Praktik Diversifikasi dan Pengembangan Produk yang telah membantu secara teknis di laboratorium.

\section{DAFTAR PUSTAKA}

[1]. Sanger G., Kaseger B.E., Rarung L. K., Damongilala L. 2018. Potensi Beberapa Jenis Rumput Laut Sebagai Bahan Pangan Fungsional, Sumber Pigmen, dan Antioksidan Alami. JPHPI, No. 2, Vol. 21, 208-217.

[2]. Merdekawati W \& Susanto. AB. 2009. Kandungan dan Komposisi Pigmen Rumput Laut serta Potensinya untuk Kesehatan. Squalen. No. 2, Vol. 4, 41-47.

[3]. Wibowo, Lukas dan Fitriyani, Evi. 2012. Pengolahan Rumput Laut (Eucheuma Cottoni) Menjadi Serbuk Minuman Instan. Vokasi. No. 2 Vol. 8, 101-109.

[4]. Afriyanto dan E. Liviawaty, 1993, Budidaya Rumput Laut dan Cara Pengolahannya, Bhratara, Jakarta.

[5]. Hudaya, R.N., 2008, Pengaruh Penambahan tepung Rumput Laut (Kappaphycus alvarezii) Untuk Peningkatan Kadar lodium Dan Serat pangan Pada Tahu Sumedang, Skripsi, Institut Pertanian Bogor, Bogor.

[6]. Jaziri, Abdul A dkk. Tanpa Tahun. Fortifikasi Tepung Eucheuma cottoni Pada Pembuatan Mie Kering. Indonesian Journal of Halal. Pusat Kajian Halal Universitas Diponegoro. Hal 109-116. 
[7]. Santoso, J., O. A. Lestari., N. A., Anugrahati, (2006). Peningkatan Kandungan Serat Makanan dan lodium pada Mie Kering melalui Substitusi tepung terigu dengan Rumput laut. Jurnal IImu Teknologi Pangan, 4(2): 131-145.

[8]. Estiasih, Teti., Harijono, Waziiroh, Elok., Fibrianto, Kiki., 2016, Kimia dan FisikPangan, Bumi Aksara, Jakarta.

[9]. Winarno, F. G. 1997, Kimia Pangan dan Gizi, Gramedia Pustaka Utama, Jakarta.

[10]. Michael E.J.L., 2013, IImu Pangan, Gizi, dan Kesehatan, Ed. I, diterjemahkan oleh: Nata Nilamsari \& Astri Fajriyah, Pustaka Belajar, Yogyakarta.

[11]. Cahyadi, Wisnu., 2012, Bahan Tambahan Pangan, Bumi Aksara, Jakarta. 